\title{
Comparison of photoscreeners and hand-held autorefractometer with cycloplegic autorefraction as a vision screening tool for children with newly diagnosed attention deficit hyperactivity disorder
}

\section{Duygu Yalinbas ( $\nabla$ duyguyalinbas@gmail.com )}

Cumhuriyet Universitesi Tip Fakultesi https://orcid.org/0000-0001-9001-0277

\section{Caner Kara}

Ankara Etlik Ihtisas Hastanesi

Seda Aybuke Sari

Cumhuriyet Universitesi Tip Fakultesi

Demet Dursun

Cumhuriyet Universitesi Tip Fakultesi

Erman Bozali

Cumhuriyet Universitesi Tip Fakultesi

\section{Research Article}

Keywords: Attention deficit hyperactivity disorder, vision screening, photosccreener, autorefractometer, children, cycloplegia

Posted Date: May 17th, 2021

DOl: https://doi.org/10.21203/rs.3.rs-178270/v2

License: (c) (i) This work is licensed under a Creative Commons Attribution 4.0 International License.

Read Full License 


\section{Abstract}

Purpose: To compare non-cycloplegic refraction measurements of two photoscreeners and the hand-held autorefractometer with cycloplegic measurements of the autorefractometer in patients with attention deficit hyperactivity disorder (ADHD).

Methods: This cross-sectional, comparative study consisted of 53 children who were newly diagnosed with ADHD. We compared spherical, cylindrical, cylindrical axis and spherical equivalent (SE) measurements in Plusoptix A12, Spot Vision Screener, and Retinomax K-plus Screen with Tonoref II. Reliability was analyzed by using the interclass correlation coefficient (ICC) and Bland-Altman plot was used to evaluate the agreement between devices.

Results: The mean age of children was $9.45 \pm 1.68$. All of the devices measured spherical power and SE significantly more myopic than the Tonoref II. While The Spot Vision Screener, PlusoptiX A12, and Tonoref II provided similar cylindrical power, Retinomax K-plus Screen measured significantly lower than the Tonoref II. The excellent reliability was detected in spherical power, cylindrical power, SE and J0 between Tonoref II and PlusoptiX A12 (ICC:0.930, 0.921, 0.927 and 0.920, respectively. All of the hand-held devices showed excellent reliability in terms of cylindrical power and J0 (ICC $>0.90$, for all) and good reliability for J45 (ICC:0.75-0.90 for all).

Conclusion: Despite all devices having advantages or disadvantages, Plusoptix A12 showed excellent reliability for detecting refractive errors in children with ADHD.

\section{Introduction}

Attention deficit hyperactivity disorder (ADHD) is one of the most prevalent neurodevelopmental disorder among children and adolescents aged between 6-17 years. The prevalence of ADHD was reported as 2\%$18 \%$ in different studies. The characteristics of ADHD are inattention, increased hyperactivity, impulsivity, and lack of controlling inappropriate behaviors ${ }^{1}$. To date, several studies have been conducted in children with ADHD in terms of ocular abnormalities such as refractive errors, ocular pathologies, and ocular side effects of agents, methylphenidate, and atomoxetine used for the treatment of $\operatorname{ADHD} 2,3$.

It is known that refractive errors and amblyopia were higher in children with ADHD. Visual problems such as refractive errors may lead to the diminution of visual acuity and concentration and contribute symptoms of $\mathrm{ADHD}^{3}$. Thus, it is essential to have an eye examination as a part of complete physical and psychological evaluation in children with ADHD and rule out underlying ocular disorders that may affect children's attention ${ }^{4}$. However, children diagnosed with ADHD may have difficulties and limitations in adapting to the measuring devices used for the ophthalmologic examination which starts with refraction assessment due to the symptoms of inattention, mobility, and impulsivity, and therefore inappropriate measurements may be obtained ${ }^{5,6}$. 
Accurate measurement of the refraction values is crucial in determining the refractive errors, appropriate treatment, and prevention of amblyopia. The cycloplegic refraction, which eliminates accommodation, is the gold standard for detecting refractive errors in children ${ }^{7}$. However, cycloplegic medications can cause unwanted side effects and may be difficult to administer to children each time. Moreover, it takes about 30-45 minutes to reach full cycloplegia, making the process time consuming ${ }^{8}$. Automated refractometers need cycloplegia in children, and table-mounted design can make it challenging to maintain proper position, and providing visual fixation on a target for a sufficient period may be arduous in uncooperative patients ${ }^{7}$. Although the main measurement methods for detecting refractive errors in children are cycloplegic assessments, both photoscreeners and hand-held autorefractometers are alternatives for vision screening in a short time for physically and mentally disabled, non-cooperative patients such as children with $\mathrm{ADHD}$ 6,7.

In this context, the aim of our study is to compare non- cycloplegic refraction measurements of two photoscreeners (Plusoptix A12 and Spot vision screener) and the hand-held autorefractometer (Retinomax K-plus Screen) with cycloplegic measurements of the autorefractometer (Tonoref II).

\section{Material Methods}

\section{Study population and study design}

This cross-sectional, comparative study consisted of 53 children aged 6-12 years who were newly diagnosed with ADHD in our university Child and Adolescent Psychiatry Department between 01.03.2020 and 01.01.2021. The Local Ethics Committee approved the study design and procedures, which were conducted in accordance with the principles outlined in the Declaration of Helsinki. Written informed consent was obtained from all participants and parents of children.

Attention deficit hyperactivity disorder was diagnosed according to the Diagnostic and Statistical Manual of Mental Disorders (DSM-V) criteria. Also, all children were evaluated by a child psychiatrist with a semi-structured interview to confirm the diagnosis of ADHD and to determine whether the child had any other psychiatric disorder. After the diagnosis of ADHD, these children were referred to the ophthalmology department for an ophthalmological examination. Children with pure ADHD and drug-naive, and without any ocular pathologies except refractive errors were included in the study. Patients were excluded from the study if they had mental retardation, specific learning disabilities, and autism spectrum disorders accompanying ADHD that could adversely affect visual examinations. Additionally, children with ptosis, strabismus, corneal and lens opacities, retinal abnormalities, and refractive errors beyond limits measurements according to manufacturers' recommendations were excluded. All of the patients underwent a complete ophthalmic examination, including pupil reactions, Hirschberg's test, cover-uncover, alternate cover tests, slit-lamp biomicroscopy, and dilated fundus examination.

\section{Measurements}


The refraction measurements of 106 eyes of 53 children were obtained in the same semi-lit room and the following order, and an average of three consecutive measurements for each device was recorded. Firstly, without cycloplegia, PlusoptiX A12 (Plusoptix GmbH, Nuremberg, Germany), Spot Vision Screener (Welch Allyn, Skaneateles Falls, NY), and Retinomax K-plus Screen (Righton, Tokyo, Japan) were performed respectively. Then, cycloplegia was induced by using cyclopentolate 1\% (Sikloplejin; Abdi İbrahim, Istanbul, Turkey) eye drops two times with an interval of 5 minutes. After 45 minutes, pupillary light reactions were checked, and complete cycloplegia was accomplished. The cycloplegic measurements were performed by Tonoref II (Nidek Co. Ltd, Gamagori, Japan). The accuracy of the cycloplegic refractive measurements in children via table-mounted autorefractometers has been demonstrated previously 9,10 .

We also evaluated the amblyogenic risk factors according to the American Association for Pediatric Ophthalmology and Strabismus (AAPOS) referral criteria for ages $>48$ months, published in $2013^{11}$.

\section{PlusoptiX A12 (Plusoptix GmbH, Nuremberg, Germany)}

PlusoptiX A12 is a hand-held photorefractor, particularly for infants, children, and uncooperative patients, to measure refractive errors without cycloplegia. The device provides measurements of both eyes simultaneously within one second from a one-meter distance. The device uses sound and lights for fixation target and measures pupil size, interpupillary distance, and ocular alignment. Besides, Plusoptix offers a referral recommendation for ophthalmologic examination based on pre-determined referral criteria $^{8}$. The device has a measurement range from -7.0 to $5.0 \mathrm{D}$ for both spherical and cylindrical measurements.

\section{Spot Vision Screener (Welch Allyn, Skaneateles Falls, NY)}

The Spot Vision Screener is a hand-held photorefractor that provides measurements of both eyes simultaneously within two seconds from a distance of 1 meter without cycloplegia. The Spot Vision Screener uses random LED visual patterns and audible sound for fixation target and provides a report including pupillary diameter, eye alignment, and estimated refraction errors. The Spot Vision Screener also gives a warning for referral a complete eye examination according to the preprogrammed referral criteria ${ }^{6}$. The device can make spherical measurements at a range of -7.50 to $7.50 \mathrm{D}$ and cylindrical measurements at a range of -3.00 and $3.00 \mathrm{D}$.

\section{Retinomax K-plus Screen (Righton, Tokyo, Japan)}

The Retinomax K-plus Screen is a portable, hand-held autorefraction keratometer with a 3.5-inch monitor. The device provides a monocular measurement of refractive errors from a distance of $5 \mathrm{~cm}$. Retinomax is both an autorefractor and a keratometer and uses a fogging mechanism to control accommodation ${ }^{12}$. The device also provides a quick mode in which measurements are taken in one second, and a melody is played to catch children's attention. The constantly changing color screen inside and outside of the device involves children in the examination throughout the process. The device can make spherical measurements at a range of $-20.0 \mathrm{D}$ to $23.0 \mathrm{D}$ and cylindrical measurements at a range of $0 \mathrm{D}$ to $\pm 12 \mathrm{D}$ 
Tonoref II is an automatic non-contact tonometer and autorefractometer. The device is mounted on the table, and the patients' forehead must be placed on the forehead of the device to take measurements. The measurement range of the device is from -30.00 to $+25.00 \mathrm{D}$ for spherical and from $0 \mathrm{D}$ to $\pm 12 \mathrm{D}$ for cylindrical measurements.

\section{Study outcomes}

Spherical, cylindrical, cylindrical axis, and spherical equivalent (SE) measurements acquired from four devices were evaluated. While calculating SE with [sphere+(cylinder power/2) ] formula, the cylindrical and axis components were transformed into vectorial representations due to the problems related to the analysis of the astigmatic component in the traditional form with the following formulas ${ }^{13}$ :

Jackson cross-cylinder at axis $0^{\circ}:(\mathrm{J} 0)=(-[\operatorname{cylinder}(\mathrm{D}) / 2] \cos [2 \times \mathrm{a}])$; Jackson cross-cylinder at axis $45^{\circ}:(J 45)=(-[$ cylinder (D)/2] $\sin [2 \times \mathrm{a}])$.

The $\mathrm{C}$ and a represent the negative cylindrical value, and axis in the radians, respectively. The $\mathrm{J} 0$ value identifies the powers at $90^{\circ}$ and $180^{\circ}$. Negative $\mathrm{J} 0$ values indicate against-the-rule astigmatism, whereas positive $\mathrm{J} 0$ values indicate with-the-rule astigmatism. The $\mathrm{J} 45$ value defines oblique astigmatism. Positive $\mathrm{J} 45$ values identify the astigmatic component at $135^{\circ}$, and negative values do so at $45^{\circ}$.

\section{Statistical Analysis}

The normality of the data was evaluated with the Kolmogorov-Smirnov test. Age and refractive measurements were presented as mean \pm standard deviation. Categorical variables were stated as number ( $\mathrm{n}$ ) and percentage (\%). The difference between measurements was assessed by the one-sample t-test. About $95 \%$ confidence interval of the difference between the compared methods was also calculated. Bland-Altman plot was used to evaluate the agreement between devices, and $95 \%$ limits of agreement (LoA) were determined for spherical equivalent, J0, and $\mathrm{J} 45$ values. Reliability was analyzed by using the interclass correlation coefficient (ICC). Based on the $95 \%$ confidence interval, reliability was divided into four groups as follows: values less than 0.5 as low, between $0.5-0.75$ as moderate, 0.75-0.9 as good, and higher than 0.9 as excellent reliability. Data obtained in the study were analyzed using Statistical Package for the Social Science software version 20 (IBM, SPSS 20 for Windows. Armonk, NY, USA). A value of $p<0.05$ was considered statistically significant.

\section{Results}

106 eyes of 53 children who completed all of the measurements were taken into the analysis. The mean age of children was $9.45 \pm 1.68$ years. Eleven (21\%) of the children were female, and 42 ( $79 \%)$ of those were male. We evaluated the measurements in Table 1 and Table 2, which were designed to define and compare the spherical power, cylindrical power, axis, spherical equivalent, J0 and J45 values between 
devices. Also, Bland-Altman plots for comparing devices in terms of spherical equivalent, J0, and J45 values are shown in figure 1 . Also, the ARF rate in the study group was detected to be $24.5 \%$.

The mean spherical power was $0.5 \pm 1.25,0.46 \pm 1.35,0.04 \pm 1.48$, and $0.78 \pm 1.72$ in Spot Vision Screener, PlusoptiX A12, Retinomax K-plus Screen, and Tonoref II, respectively. All of the devices measured spherical power significantly more myopic than the Tonoref II ( $p<0.001$ for PlusoptiX A12 and Retinomax K-plus Screen, and $\mathrm{p}=0.003$ for Spot Vision Screener).

The mean cylindrical power was $-0.89 \pm 0.97,-0.7 \pm 0.65,-0.69 \pm 0.81$ and,$-0.80 \pm 0.83$ in Spot Vision Screener, PlusoptiX A12, Retinomax K-plus Screen, and Tonoref II, respectively. The Spot Vision Screener, PlusoptiX A12, and Tonoref II provided similar cylindrical power ( $p>0.05$ for both comparisons). However, Retinomax K-plus Screen measured cylindrical power significantly lower than the Tonoref II $(p=0.001)$.

The mean axis measurements were $81.9 \pm 73.8,82.3 \pm 74.07,98.2 \pm 69.61$ and, $101.1 \pm 72.89$ in Spot Vision Screener, PlusoptiX A12, Retinomax K-plus Screen, and Tonoref II, respectively. While the Spot Vision Screener and the PlusoptiX A12 measured axis significantly lower than the Tonoref II $(p=0.008$ and $p=0.02)$, Retinomax K-plus Screen and Tonoref II provided similar results in terms of axis measurements $(p=0.6)$.

The distributions of differences between the three devices in terms of SE, J0, and $\mathrm{J} 45$ values were shown in figure 2. The mean SE, J0, and J45 measurements were $0.05 \pm 1.14,0.36 \pm 0.51$ and $0.018 \pm 0.2$ in Spot Vision Screener, $0.1 \pm 1.28,0.28 \pm 0.35$ and $0.011 \pm 0.18$ in PlusoptiX A12, $-0.3 \pm 1.41,0.24 \pm 0.43$ and $-0.02 \pm 0.22$ in Retinomax K-plus Screen, and $0.38 \pm 1.65,0.31 \pm 0.42$ and $-0.026 \pm 0.21$ in Tonoref II respectively. All of the devices measured SE significantly more myopic than the Tonoref II $(p<0.001$ for PlusoptiX A12 and Retinomax K-plus Screen, and $p=0.002$ for Spot Vision Screener). The difference of J0 was similar between Spot Vision Screener, PlusoptiX A12, and Tonoref II. However, Retinomax K-plus Screen measured J0 significantly lower than the Tonoref II $(p<0.001)$. On the other hand, the mean difference of J45 was similar between Retinomax K-plus Screen and the Tonoref II $(p=0.7)$.

Table 3 summarizes the ICC between devices in terms of spherical power, cylindrical power, axis, SE, J0, and $\mathrm{J} 45$ values. The reliability of measurements between devices was variable. However, the best reliability results were obtained between Tonoref II and PlusoptiX A12. While excellent reliability was detected in spherical power, cylindrical power, SE and J0 between Tonoref II and PlusoptiX A12 [interclass correlation coefficient (ICC):0.930, 95\% confidence interval (CI):0.801-0.909; ICC:0.921, 95\%Cl:0.8820.947; ICC: $0.927,95 \% \mathrm{Cl}: 0.891-0.951$; and ICC: $0.920,95 \% \mathrm{Cl}: 0.880-0.946$, respectively], good reliability was determined in axis and J45 (ICC:0.752, 95\%Cl:0.685-0.852 and ICC:0.845, 95\% Cl:0.769-0.897, respectively).

\section{Discussion}

Previous studies showed that children with ADHD had a higher prevalence of refractive errors such as astigmatism, hypermetropia and amblyopia, Hence, vision screening is crucial for the early detection of 
refractive errors and prevent amblyopia in these children ${ }^{3,5,14}$. In this context, this is the first study that compares the noncycloplegic refraction measurement values obtained by Spot Vision Screener, PlusoptiX A12, and Retinomax K-plus Screen, and cycloplegic values by Tonoref II in children with ADHD. Although noncycloplegic measurements of hand-held devices underestimate or overestimate the values in terms of spherical and cylindrical powers, axis, SE, J0, and J45 compared to cycloplegic measurements of autorefractometer, PlusoptiX A12 had an excellent interclass correlation with Tonoref II regarding the spherical and cylindrical powers, SE, and J45.

Studies investigating the visual function and ocular abnormalities in children with ADHD reported a higher frequency of reduced visual acuity, subnormal stereoacuity, refractive errors, convergence abnormalities, small optic discs, heterophoria, and cognitive visual problems ${ }^{14}$. Ocular abnormalities in ADHD were explained by various mechanisms consisting of neurological dysfunctions in cortical regions, inhibition impairment, decrease in the optic nerve's axonal volume, and balance control failure ${ }^{3}$.

In children with ADHD, amblyopia, hypermetropia, astigmatism, and heterotropia were found 1.89, 1.82, 1.73 , and 2.01 times more likely than without ones in a population based study ${ }^{3}$. Refractive errors may contribute to a decrease in concentration, leading to more evident symptoms of inattention and hyperactivity. Astigmatism and hyperopia affect both near and distance vision, unlike myopia, which affects only distance vision. Accordingly, astigmatism and hyperopia can affect an individual's attentional abilities more than myopia. In particular, uncorrected hyperopia and astigmatism, and amblyopia were found to be associated with reading impairment and thus academic performance ${ }^{15,16}$. Therefore, detecting refractive errors is also important in the differential diagnosis of learning disabilities accompanying $A D H D{ }^{17}$.

Amblyopia is a common, preventable cause of visual impairment in children and adults with a prevalence of $1.6-3.6 \%$ and one of the associated risk factors is uncorrected refractive errors. Higher prevalences of amblyopia in ADHD were mentioned in previous studies above. Furthermore, in a recent study, it was reported that the risk of developing ADHD is higher ( $1.81 \mathrm{fold}$ ) in children with amblyopia. The relationship between ADHD and amblyopia was speculated on sharing similar predisposing factors such as developmental delay, mental retardation, and respiratory allergic diseases ${ }^{18}$. Although the ARF rate may differ according to study groups, in our study group, the ARF rate at $24.5 \%$ was higher than the ARF rate which is $3.6 \%$ in the general population ${ }^{19}$.

Photoscreeners and hand-held autorefractometers have been used for screening refractive errors, and several studies were conducted to compare devices in healthy school-aged children and also some specific patient populations, including autism and intellectual disability $7,20,21$. However, there was no study comparing non-cycloplegic measurements of photoscreeners and hand-held autorefractometers with cycloplegic measurements in children with ADHD in the literature.

Teberik et al. evaluated the comparison of non-cycloplegic measurements of three different photoscreeners consist of Plusoptix A12, Spot Vision Screener, and Retinomax K-plus 3 with cycloplegic 
autorefractometer measurements in healthy school-aged children. They reported that Plusoptix A12 had compatible results with cycloplegic autorefractometer in all measurements, but the integration level was moderate. ${ }^{7}$. The accuracy of Plusoptix A12 was reported better in the myopic, astigmatic, and anisometropic eyes than hyperopic eyes due to underestimating hyperopic refractive errors ${ }^{19}$. Similarly, in our study, although PlusoptiX A12 underestimates hyperopia of 0.39 D, the device had an excellent interclass correlation with Tonoref II regarding the spherical and cylindrical powers, SE, and J45 in children with ADHD. The Plusoptix was found very useful compared with cycloplegic retinoscopy, especially in determining axis and cylinder power in various studies ${ }^{22}$. Ugurbas et al. evaluated the validity of Plusoptix S04 as a vision screening device and reported that non-cycloplegic measurements of the device are accurate for children with intellectual disability ${ }^{20}$. Furthermore, in a study by McCurry et al., it was reported that vision screening with Plusoptix S08 reduced the full ophthalmologic examination requirement in one-third of the screening children with autism ${ }^{21}$.

Yilmaz et al. evaluated the comparison of Plusoptix A09 (non-cycloplegic) and Retinomax K-Plus-3 (cycloplegic) with retinoscopy (cycloplegic) in children. Both devices showed high agreement (ICC greater than 0.90 for all) with cycloplegic retinoscopy in terms of spherical power, cylindrical power, and SE. In our study, the Retinomax K-plus Screen acquired more myopic SE values compared other three devices, and the ICC showed good reliability (ICC between 0.75 and 0.90 ) in terms of spherical power, SE and J45. The difference between the two studies in terms of spherical values may have resulted from the inability of non-cycloplegic measurements to eliminate accommodation in our study, unlike Yilmaz et al ${ }^{23}$. Additionally, previous studies confirmed that non-cycloplegic measurements of Retinomax devices were inaccurate. However, under cycloplegia, Retinomax had similar accuracy compared with retinoscopy and table-top autorefractometer in terms of spherical, cylindrical, and SE values ${ }^{24}$. Nevertheless, in another study, non-cycloplegic measurements of Retinomax demonstrated better results than photoscreening in terms of astigmatism and similar results in terms of hyperopia ${ }^{25}$. Similarly, in our study, the Retinomax K-plus Screen had excellent reliability (ICC greater than 0.90) in terms of cylindrical power and J0. Akil et compared the cycloplegic and non- cycloplegic refractive measurements of Retinomax K-plus 3 and tabletop autorefractokeratometer with cycloplegic retinoscopy. They found a good agreement between Retinomax and autorefractokeratometer in $\mathrm{J} 0$ and $\mathrm{J} 45$, unaffected by cycloplegia ${ }^{12}$.

The Spot Vision Screener has demonstrated good sensitivity and moderate specificity in detecting ARFs in children with developmental disabilities ${ }^{6}$. Teberik et al. reported moderate integration levels between non-cycloplegic measurements of Spot and cycloplegic measurements of autorefractometer in terms of spherical, cylindrical, and SE values ${ }^{7}$. In another study, Spot was found with high specificity to detect refractive errors; however, the sensitivity was found low for hyperopia ${ }^{26}$. In our study, we found excellent reliability in terms of cylindrical power and J0. However, there was a $0.33 \mathrm{D}$ myopic shift of SE compared to cycloplegic measurements. Similarly, Qian et al. indicated that Spot had a myopic shift of $0.17 \mathrm{D}$ compared to cycloplegic retinoscopy. They also reported that $\mathrm{J} 0$ and $\mathrm{J} 45$ values had medium correlations 
with cycloplegic retinoscopy. Nevertheless, the Spot was found to strongly agree with cycloplegic retinoscopy for the refractive error and strabismus evaluation 27 .

Small sample size, absence of cycloplegic measurements with hand-held autorefractometers, examination of both eyes of the children, and lack of comparison of the devices in terms of detecting ARFs are the limitations of this study. The cycloplegic retinoscopy has been used as the gold standard for refractive error measurements in most studies. However, in the present study cycloplegic autorefraction was utilized as a gold standard instead of retinoscopy. Given the controversy that this standardization might be debated, the validity of cycloplegic autorefraction for refractive error examination in children has been approved to be accurate and in sync with cycloplegic retinoscopy previously 9, 28, 29 .

\section{Conclusions}

Novel vision screening programs are widely used for detecting visual problems in children. In our study, all of the hand-held devices showed excellent reliability in terms of cylindrical power and $\mathrm{J} 0$ and good reliability for $\mathrm{J} 45$. This may guide for prescribing cylindrical power and axis; however, cycloplegic measurements may be necessary for prescribing accurate spherical values. Even though all devices had advantages or disadvantages, Plusoptix A12 showed excellent reliability for detecting refractive errors in children with ADHD. The elimination of the cycloplegia requirement, remote measurement, and short examination time in these children may increase patient compliance.

\section{Declarations}

\section{Acknowledgement}

This article has a preprint form (adres)

Conflict of interest / Competing interest: All of the authors declare they have no conflict of interest

Funding info: This research did not receive any specific grant from funding agencies in the public, commercial, or not-for-profit sectors.

Authors contributions: DY: conceptualization, writing-original draft, formal analysis, methodology; CK: supervision, formal analysis, methodology; SAS: resource, writing-review editing; DD: investigation; EB: investigation, writing-review editing

\section{References}

1. Karaca I, Biler ED, Onay MP, Özbaran B and Üretmen Ö. Stereoacuity, Fusional Vergence Amplitudes, and Refractive Errors Prior to Treatment in Patients with Attention-Deficit Hyperactivity Disorder. Turkish Journal of Ophthalmology. 2020; 50: 15. 
2. Larrañaga-Fragoso P, Noval S, Rivero JC and Boto-de-los-Bueis A. The effects of methylphenidate on refraction and anterior segment parameters in children with attention deficit hyperactivity disorder. Journal of American Association for Pediatric Ophthalmology and Strabismus. 2015; 19: 322-6.

3. Ho J-D, Sheu J-J, Kao Y-W, Shia B-C and Lin H-C. Associations between AttentionDeficit/Hyperactivity Disorder and Ocular Abnormalities in Children: A Population-based Study. Ophthalmic Epidemiology. 2020; 27: 194-9.

4. Ababneh LT, Bashtawi M, Ababneh BF, Mahmoud IH, Rashdan M and Zahran M. Ocular findings in children with attention deficit hyperactivity disorder: A Case-Control study. Annals of Medicine and Surgery. 2020; 57: 303-6.

5. Mezer E and Wygnanski-Jaffe T. Do children and adolescents with attention deficit hyperactivity disorder have ocular abnormalities? European journal of ophthalmology. 2012; 22: 931-5.

6. Marzolf AL, Peterseim MM, Forcina BD, et al. Use of the Spot Vision Screener for patients with developmental disability. Journal of American Association for Pediatric Ophthalmology and Strabismus. 2017; 21: 313-5. e1.

7. Teberik K, Eski MT, Kaya M and Ankarali H. A comparison of three different photoscreeners in children. Journal of Pediatric Ophthalmology and Strabismus. 2018; 55: 306-11.

8. Yilmaz I, Ozkaya A, Alkin Z, Ozbengi S, Yazici AT and Demirok A. Comparison of the Plusoptix A09 and Retinomax K-Plus 3 with retinoscopy in children. Journal of pediatric ophthalmology and strabismus. 2015; 52: 37-42.

9. Prabakaran S, Dirani M, Chia A, et al. Cycloplegic refraction in preschool children: comparisons between the hand-held autorefractor, table-mounted autorefractor and retinoscopy. Ophthalmic Physiol Opt. 2009; 29: 422-6.

10. Choong Y-F, Chen A-H and Goh P-P. A comparison of autorefraction and subjective refraction with and without cycloplegia in primary school children. Am J Ophthalmol. 2006; 142: 68-74. e1.

11. Donahue SP, Arthur B, Neely DE, et al. Guidelines for automated preschool vision screening: a 10-year, evidence-based update. Journal of American Association for Pediatric Ophthalmology and Strabismus. 2013; 17: 4-8.

12. Akil $\mathrm{H}$, Keskin $\mathrm{S}$ and Çavdarli $\mathrm{C}$. Comparison of the refractive measurements with hand-held autorefractometer, table-mounted autorefractometer and cycloplegic retinoscopy in children. Korean J Ophthalmol. 2015; 29: 178-84.

13. Thibos $L N$, Wheeler $W$ and Horner $D$. Power vectors: an application of Fourier analysis to the description and statistical analysis of refractive error. Optom Vis Sci. 1997; 74: 367-75.

14. Grönlund $M$, Aring E, Landgren $M$ and Hellström A. Visual function and ocular features in children and adolescents with attention deficit hyperactivity disorder, with and without treatment with stimulants. Eye. 2007; 21: 494-502.

15. Birch EE and Kelly KR. Pediatric ophthalmology and childhood reading difficulties: amblyopia and slow reading. Elsevier, 2017 
16. Collins ME, Mudie LI, Inns AJ and Repka MX. Pediatric ophthalmology and childhood reading difficulties: Overview of reading development and assessments for the pediatric ophthalmologist. Journal of American Association for Pediatric Ophthalmology and Strabismus. 2017; 21: 433-6. e1.

17. Bilbao $C$ and Piñero DP. Diagnosis of oculomotor anomalies in children with learning disorders. Clinical and Experimental Optometry. 2020; 103: 597-609.

18. Su CC, Tsai CY, Tsai TH and Tsai IJ. Incidence and risk of attention-deficit hyperactivity disorder in children with amblyopia: A nationwide cohort study. Clin Experiment Ophthalmol. 2019; 47: 259-64.

19. Fogel-Levin M, Doron R, Wygnanski-Jaffe T, Ancri $O$ and Zion IB. A comparison of plusoptiX A12 measurements with cycloplegic refraction. Journal of American Association for Pediatric Ophthalmology and Strabismus. 2016; 20: 310-4.

20. Ugurbas SC, Alpay A, Efe YK, Ugurbas SH, Tutar H and Sagdik HM. Validity of plusoptiX S04 photoscreener as a vision screening tool in children with intellectual disability. Journal of American Association for Pediatric Ophthalmology and Strabismus \{JAAPOS\}. 2011; 15: e14-e5.

21. McCurry TC, Lawrence LM, Wilson ME and Mayo L. The plusoptiX S08 photoscreener as a vision screening tool for children with autism. Journal of American Association for Pediatric Ophthalmology and Strabismus. 2013; 17: 374-7.

22. Saini V, Raina UK, Gupta A, et al. Comparison of Plusoptix S12R photoscreener with cycloplegic retinoscopy and autorefraction in pediatric age group. Indian journal of ophthalmology. 2019; 67: 1555.

23. Mirzajani A, Qasemi F, Asharlous A, et al. Are the results of handheld auto-refractometer as valid as the result of table-mounted refractometer? Journal of current ophthalmology. 2019; 31: 305-11.

24. Tuncer I, Zengin MO and Karahan E. Comparison of the Retinomax hand-held autorefractor versus table-top autorefractor and retinoscopy. International journal of ophthalmology. 2014; 7: 491.

25. Cordonnier $M$ and Kallay $\mathrm{O}$. Non-cycloplegic screening for refractive errors in children with the handheld autorefractor Retinomax: final results and comparison with non-cycloplegic photoscreening. Strabismus. 2001; 9: 59-70.

26. Barugel R, Touhami S, Samama S, et al. Evaluation of the Spot Vision Screener for children with limited access to ocular health care. Journal of American Association for Pediatric Ophthalmology and Strabismus. 2019; 23: 153. e1-. e5.

27. Qian X, Li Y, Ding G, et al. Compared performance of Spot and SW800 photoscreeners on Chinese children. Br J Ophthalmol. 2019; 103: 517-22.

28. Yassa ET and Ünlü C. Comparison of Autorefraction and Photorefraction with and without Cycloplegia Using 1\% Tropicamide in Preschool Children. Journal of ophthalmology. 2019; 2019.

29. Demirci G, Arslan B, Özsütçü M, Eliaçık M and Gulkilik G. Comparison of photorefraction, autorefractometry and retinoscopy in children. Int Ophthalmol. 2014; 34: 739-46.

\section{Tables}


Table 1: Mean refraction values obtained with Spot Vision Screener, PlusoptiX A12, Tonoref II, and Retinomax K-plus Screen

\begin{tabular}{|l|c|c|}
\hline Group & Mean \pm SD & Range \\
\hline Spot Vision Screener (non-cycloplegic) & $0.5 \pm 1.25$ & -4 to 3.5 \\
Spherical power (D) & $-0.89 \pm 0.97$ & -4.25 to 0 \\
Cylindrical power (D) & $81.9 \pm 73.8$ & 1 to 180 \\
Axis (Degrees) & $0.05 \pm 1.14$ & -4.5 to 2.63 \\
SE (D) & $0.36 \pm 0.51$ & -0.61 to 2.12 \\
J0 (D) & $0.02 \pm 0.2$ & -0.76 to 0.51 \\
J45 (D) & & \\
\hline PlusoptiX A12 (non-cycloplegic) & \\
Spherical power (D) & & \\
Cylindirical power (D) & $0.46 \pm 1.35$ & -3.75 to 4.75 \\
Axis (Degrees) & $-0.7 \pm 0.65$ & -3 to 0 \\
SE (D) & $82.3 \pm 74.07$ & 1 to 180 \\
J0 (D) & $0.12 \pm 1.28$ & -4.12 to 3.5 \\
J45 (D) & $0.01 \pm 0.18$ & -0.25 to 1.49 \\
\hline Retinomax K-plus Screen (non-cycloplegic) & -0.47 to 0.66 \\
Spherical power (D) & $0.04 \pm 1.48$ & -4 to 5.25 \\
Cylindirical power (D) & $-0.69 \pm 0.81$ & -3.5 to 0 \\
Axis (Degrees) & $98.2 \pm 69.61$ & 1 to 183 \\
SE (D) & $-0.3 \pm 1.41$ & -5 to 3.63 \\
J0 (D) & $0.24 \pm 0.43$ & -0.35 to 1.71 \\
J45 (D) & $-0.02 \pm 0.22$ & -0.91 to 0.86 \\
Tonoref II (cycloplegic) & $-0.80 \pm 0.83$ & -4 to 0 \\
Spherical power (D) & & \\
Cylindirical power (D) & & \\
Axis (Degrees) & & \\
SE (D) & & \\
J0 (D) & & \\
J45 (D) & & \\
\hline
\end{tabular}

SD: Standard deviation, D: Diopter, SE: Spherical equivalent, J0: Jackson cross-cylinder power at axis $90^{\circ}$ and $180^{\circ}, \mathrm{J} 45$ :Jackson cross-cylinder power at axis $45^{\circ}$ and $135^{\circ}$ 
Table 2: Comparison of refraction values values obtained with Spot Vision Screener, PlusoptiX A12, Tonoref II, and Retinomax K-plus Screen

\begin{tabular}{|c|c|c|c|}
\hline Group & $\begin{array}{c}\text { Mean } \\
\text { difference } \pm S D\end{array}$ & $\begin{array}{l}\text { 95\% CI of the } \\
\text { difference }\end{array}$ & $P$ value \\
\hline $\begin{array}{l}\text { Tonoref II (cycloplegic) vs. Spot Vision Screener } \\
\text { (non-cycloplegic) } \\
\text { Spherical power (D) } \\
\text { Cylindrical power (D) } \\
\text { Axis (Degrees) } \\
\text { SE (D) } \\
\text { JO (D) } \\
\text { J45 (D) }\end{array}$ & $\begin{array}{c}0.30 \pm 1.03 \\
0.041 \pm 0.35 \\
20.8 \pm 88.7 \\
0.33 \pm 1.08 \\
-0.015 \pm 0.25 \\
-0.041 \pm 0.166\end{array}$ & $\begin{array}{c}0.106 \text { and } \\
0.509 \\
-0.028 \text { and } \\
0.110 \\
2.628 \text { and } \\
38.989 \\
0.120 \text { and } \\
0.540 \\
-0.063 \text { and } \\
0.033 \\
-0.073 \text { and } \\
-0.009\end{array}$ & $\begin{array}{c}0.003 \\
0.2 \\
0.02 \\
0.002 \\
0.5 \\
0.01\end{array}$ \\
\hline $\begin{array}{l}\text { Tonoref II (cycloplegic) vs. PlusoptiX A12 (non- } \\
\text { cycloplegic) } \\
\text { Spherical power (D) } \\
\text { Cylindirical power (D) } \\
\text { Axis (Degrees) } \\
\text { SE (D) } \\
\text { JO (D) } \\
\text { J45 (D) }\end{array}$ & $\begin{array}{c}0.39 \pm 0.76 \\
-0.062 \pm 0.35 \\
21.25 \pm 71.2 \\
0.36 \pm 0.74 \\
0.022 \pm 0.19 \\
-0.031 \pm 0.13\end{array}$ & $\begin{array}{c}0.23 \text { and } 0.54 \\
-0.134 \text { and } \\
0.009 \\
5.781 \text { and } \\
36.718 \\
0.211 \text { and } \\
0.510 \\
-0.015 \text { and } 0.06 \\
-0.059 \text { and } \\
-0.003\end{array}$ & $\begin{array}{c}<0.001 \\
0.08 \\
0.008 \\
<0.001 \\
0.2 \\
0.02\end{array}$ \\
\hline $\begin{array}{l}\text { Tonoref II (cycloplegic) vs. Retinomax K-plus } \\
\text { Screen (non-cycloplegic) } \\
\text { Spherical power (D) } \\
\text { Cylindirical power (D) } \\
\text { Axis (Degrees) } \\
\text { SE (D) } \\
\text { JO (D) } \\
\text { J45 (D) }\end{array}$ & $\begin{array}{c}0.74 \pm 1.05 \\
-0.099 \pm 0.28 \\
5.53 \pm 86.99 \\
0.69 \pm 1.08 \\
0.075 \pm 0.2 \\
-0.006 \pm 0.14\end{array}$ & $\begin{array}{c}0.534 \text { and } \\
0.946 \\
-0.155 \text { and } \\
-0.043 \\
-13.342 \text { and } \\
24.414 \\
0.481 \text { and } \\
0.903 \\
0.034 \text { and } \\
0.115 \\
-0.006 \text { and } \\
-0.033\end{array}$ & $\begin{array}{c}<0.001 \\
0.001 \\
0.6 \\
<0.001 \\
<0.001 \\
0.7\end{array}$ \\
\hline
\end{tabular}

SD: Standard deviation, CI: Confidence Interval, D: Diopter, SE: Spherical equivalent, J0: Jackson cross-cylinder power at axis $90^{\circ}$ and $180^{\circ}$, J45:Jackson cross-cylinder power at axis $45^{\circ}$ and $135^{\circ}$ 
Table 3: Interclass correlation coefficient (ICC), 95\% confidence interval and reliability of measurements

\begin{tabular}{|l|c|c|c|c|}
\hline Pairs-Parameters & ICC & $\begin{array}{c}\text { 95\%Confidence } \\
\text { Interval }\end{array}$ & P value & Reliability \\
\hline Tonoref II (cycloplegic) vs. Spot Vision & & & & \\
Screener (non-cycloplegic) & & $0.801-0.909$ & $<0.001$ & Good \\
Spherical power (D) & 0.865 & $0.934-0.970$ & $<0.001$ & Excellent \\
Cylindrical power (D) & 0.955 & $0.129-0.616$ & 0.004 & Low \\
Axis (Degrees) & 0.421 & $0.752-0.886$ & $<0.001$ & Good \\
SE (D) & 0.832 & $0.877-0.944$ & $<0.001$ & Excellent \\
JO (D) & 0.917 & $0.724-0.873$ & $<0.001$ & Good \\
J45 (D) & 0.813 & & & \\
& & & & \\
Tonoref II (cycloplegic) vs. Plusoptix A12 & & & \\
(non-cycloplegic) & 0.930 & $0.896-0.954$ & $<0.001$ & Excellent \\
Spherical power (D) & 0.921 & $0.882-0.947$ & $<0.001$ & Excellent \\
Cylindrical power (D) & 0.752 & $0.685-0.852$ & $<0.001$ & Good \\
Axis (Degrees) & 0.927 & $0.891-0.951$ & $<0.001$ & Excellent \\
SE (D) & 0.920 & $0.880-0.946$ & $<0.001$ & Excellent \\
JO (D) & 0.845 & $0.769-0.897$ & $<0.001$ & Good \\
J45 (D) & & & & \\
\hline Tonoref II (cycloplegic) vs. Retinomax K- & & & \\
plus Screen (non-cycloplegic) & & & & \\
Spherical power (D) & 0.879 & $0.821-0.918$ & $<0.001$ & Good \\
Cylindrical power (D) & 0.969 & $0.955-0.979$ & $<0.001$ & Excellent \\
Axis (Degrees) & 0.421 & $0.107-0.624$ & 0.007 & Low \\
SE (D) & 0.858 & $0.790-0.904$ & $<0.001$ & Good \\
JO (D) & 0.938 & $0.908-0.958$ & $<0.001$ & Excellent \\
J45 (D) & 0.879 & $0.822-0.918$ & $<0.001$ & Good \\
\hline
\end{tabular}

ICC: Interclass Correlation, D: Diopter, SE: Spherical equivalent, J0: Jackson cross-cylinder power at axis $90^{\circ}$ and $180^{\circ}$, J45:Jackson cross-cylinder power at axis $45^{\circ}$ and $135^{\circ}$

\section{Figures}



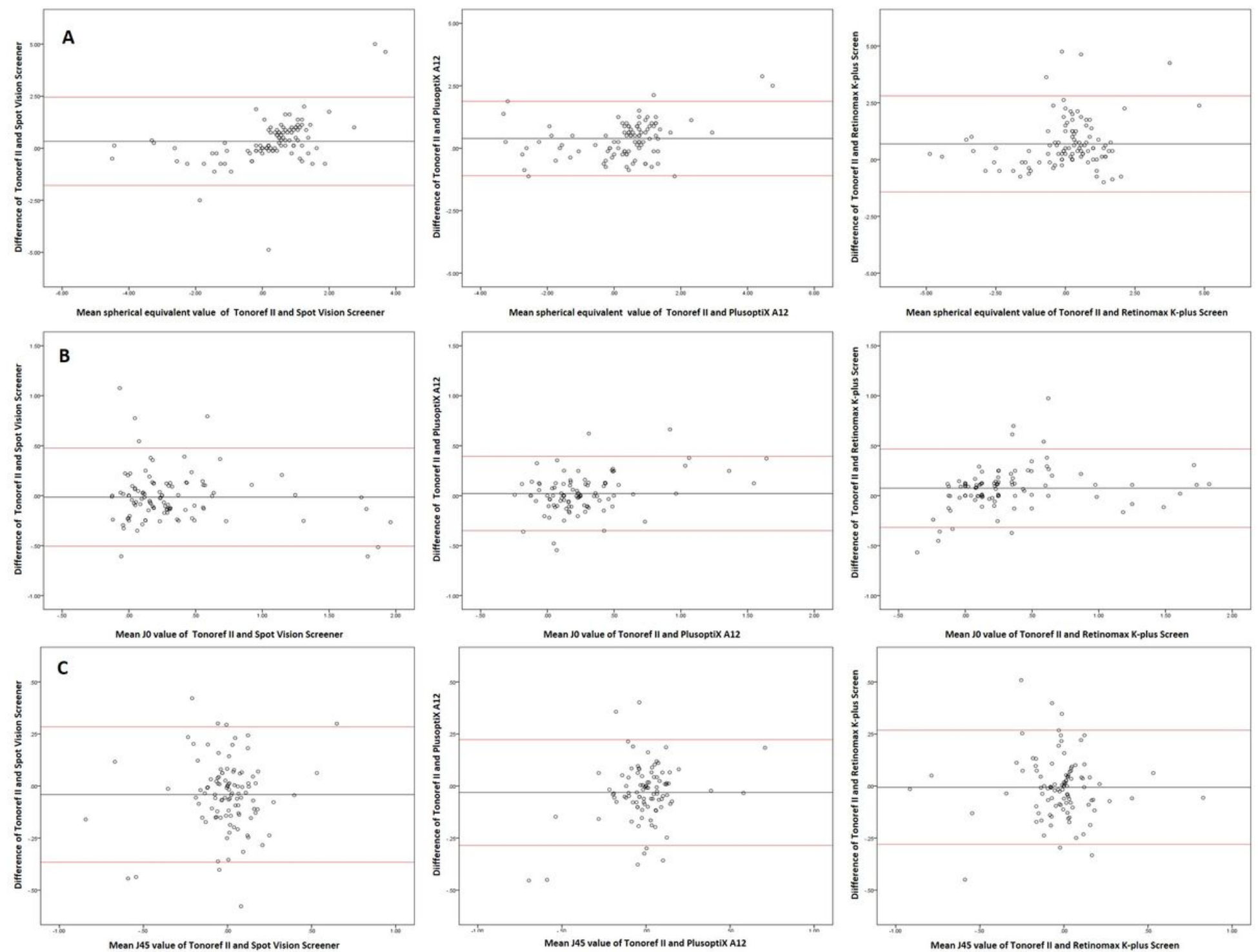

Figure 1

Bland-Altman plots showing agreement between devices in terms of spherical equivalent (A), J0 (B) and J45 (C) values. 
Distribution of the difference between spherical equivalent values
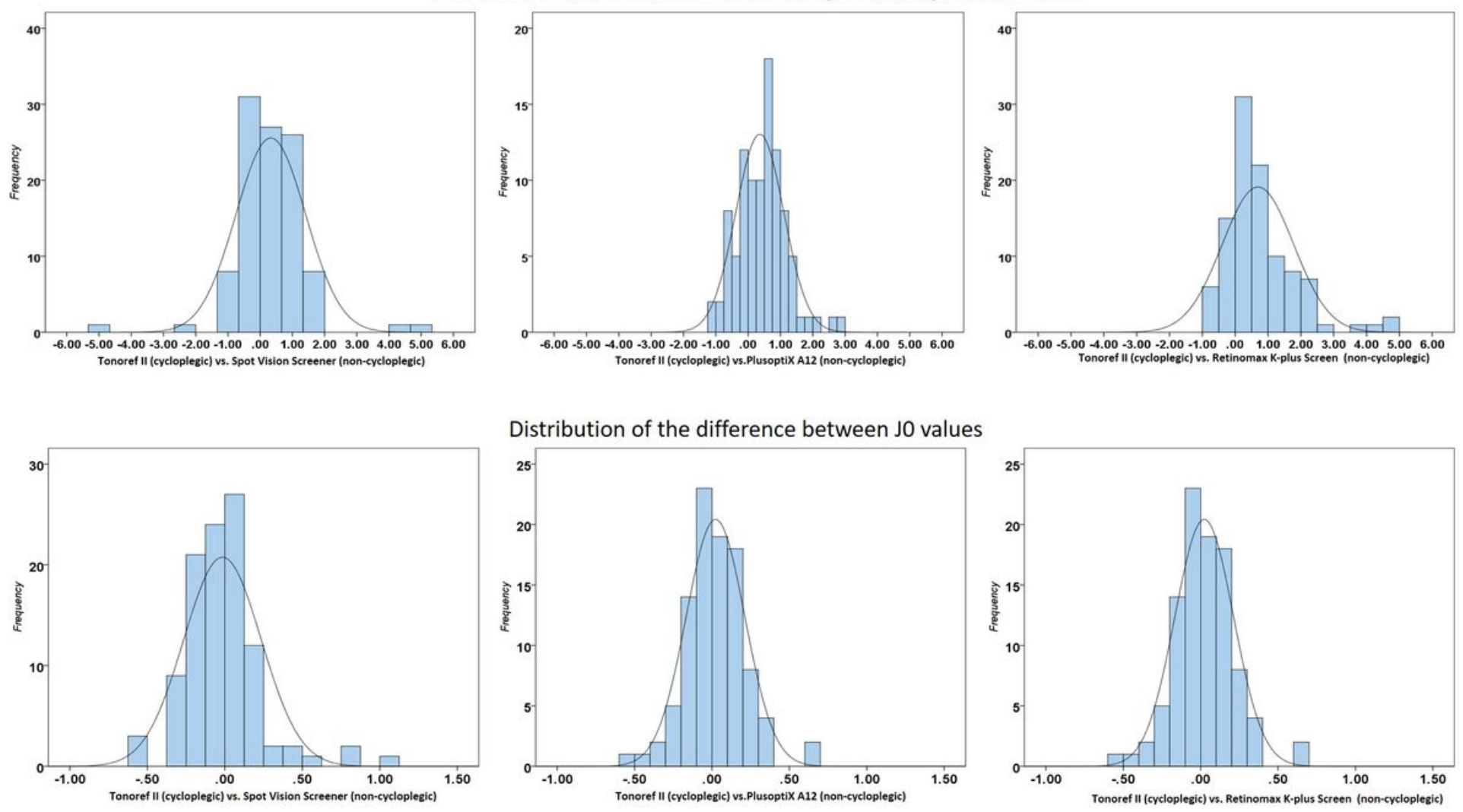

Distribution of the difference between J0 values
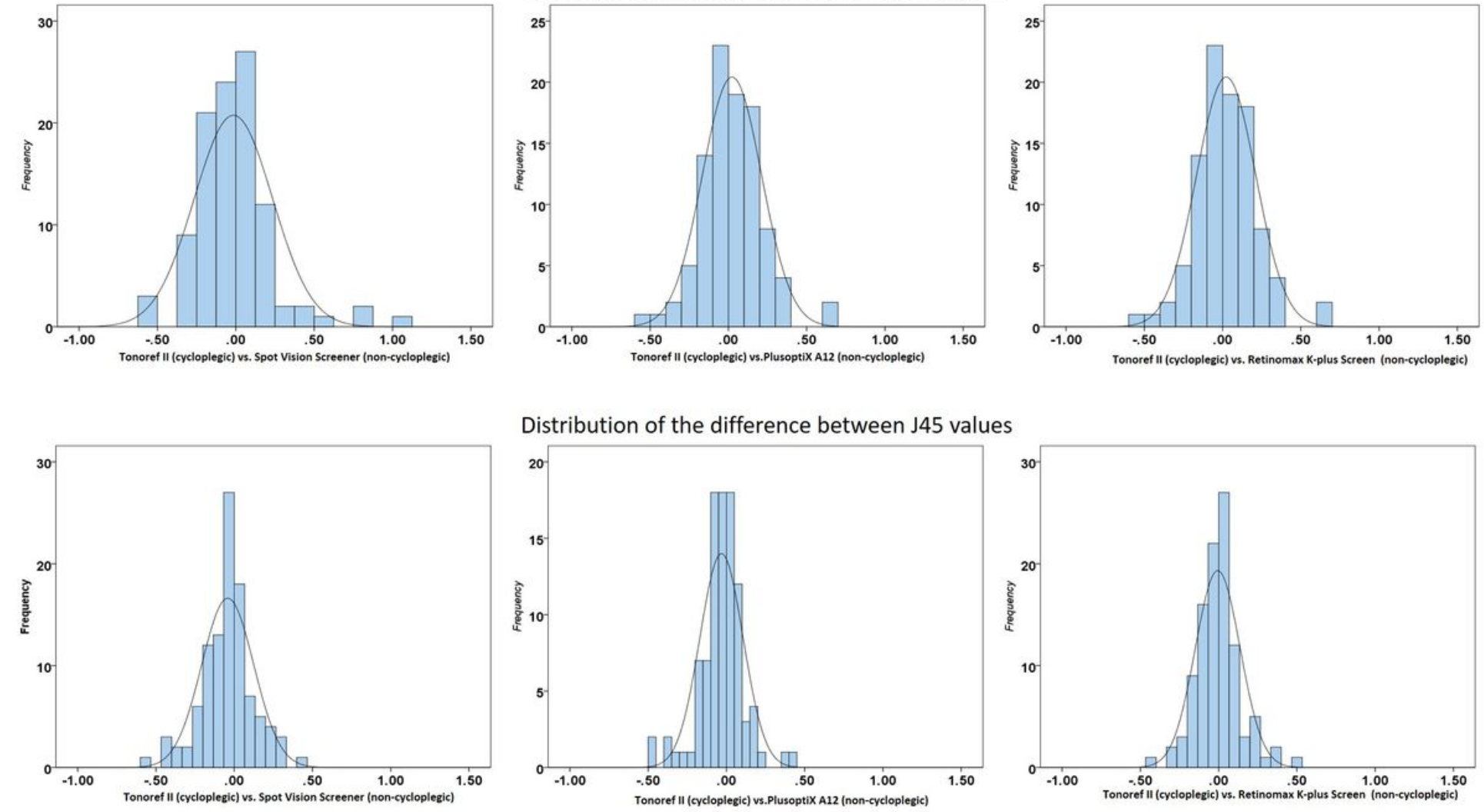

Figure 2

Frequency distribution of the differences in terms of spherical equivalent, $\mathrm{J} 0$ and $\mathrm{J} 45$ values between devices. 